\title{
Leptospira spp. Prevalence in Small Mammal Populations in Cotonou, Benin
}

\author{
G. Houemenou, ${ }^{1}$ A. Ahmed, ${ }^{2}$ R. Libois, ${ }^{1}$ and R. A. Hartskeerl ${ }^{2}$ \\ ${ }^{1}$ Unité de Recherche en Zoogéographie, Université de Liège, Bâtiment B22 Boulevard du Rectorat, 4031 Sart Tilman, Belgium \\ ${ }^{2}$ WHO/FAO/OIE and National Leptospirosis Reference Centre, KIT Biomedical Research, Meibergdreef 39, \\ 1105 AZ Amsterdam, The Netherlands
}

Correspondence should be addressed to G. Houemenou; houegual@yahoo.fr

Received 23 December 2012; Accepted 12 February 2013

Academic Editors: P. E. Cattan, C. M. Maylahn, and J. M. Ramon

Copyright (c) 2013 G. Houemenou et al. This is an open access article distributed under the Creative Commons Attribution License, which permits unrestricted use, distribution, and reproduction in any medium, provided the original work is properly cited.

\begin{abstract}
The aim of this study was to assess the Leptospira prevalence in small animals in Cotonou, the capital of Benin. Rodents and shrews were captured in urban and periurban settings and determined as species of the genera Rattus, Mastomys, and Crocidura. Kidney specimens of 90 animals were examined using a real-time PCR assay specific for leptospires that belong to pathogenic species. Leptospiral DNA was amplified from kidney tissues ranging from $13.3 \%$ (8/60) in Rattus rattus to 100.0\% (1/1) in Crocidura spp. with an average of $18.9 \%$ (17/90) of the animals caught at 15 locations. Clade-specific Taqman PCR on 10 samples placed six of these within clade 1 comprising the species L. kirschneri, L. interrogans, L. meyeri, and L. noguchii and four within clade 2 consisting of species L. weilii, L. alexanderi, L. borgpetersenii, and L. santarosai. Phylogenetic analysis of partial sequences of the amplicons of seven samples of these 10 samples revealed that four of the clade 1 samples could equally be assigned to $L$. interrogans and $L$. kirschneri and three samples from clade 2 belonged to L. borgpetersenii. Results presented in the paper indicate that small mammals present a major public health risk for acquiring leptospirosis in Cotonou, Benin and will contribute to a raised awareness amongst health care workers and decision makers and hence promote appropriate clinical management of cases.
\end{abstract}

\section{Introduction}

Leptospirosis is one of the most common bacterial zoonoses worldwide [1]. In the past decade, leptospirosis has emerged as a globally important infectious disease. Although the disease has a worldwide distribution, it is particularly common in countries with humid tropical and subtropical climates [2].

Although rodents and insectivores are notorious reservoirs of leptospires, the vast majority of domestic and feral mammalian species can be natural hosts and transient carriers of Leptospira [3-7]. The serovar is the basic taxon of leptospires. To date, more than 250 serovars have been identified [4], each of these adapted to one or more hosts.

Mus musculus (house mouse), Rattus norvegicus (brown rat), and Rattus rattus (black rat) are three species of rodents with a worldwide distribution that are commonly associated with leptospiral infection [8].

Leptospires live in the kidneys and urogenital tract of the hosts and are excreted with the urine into the environment where they can survive for several months depending on favorable humid and warm conditions.

Humans are infected through direct contact with infected animals or, indirectly, by exposure to contaminated soil and water or through consumption of contaminated food or water [9]. Humans are dead-end hosts: the risk of human-to-human transmission probably is insignificant [1].

Leptospirosis infection in humans presents with symptoms that are similar to that of other better known parasitic, viral, and bacterial infections such as malaria, dengue, and other viral haemorrhagic fevers, salmonellosis, and brucellosis. Hence, leptospirosis is frequently misdiagnosed and, notably, its impact on African communities largely lacks documentation.

Although the disease is most common in tropical and rural settings, leptospirosis is considered as an increasing urban problem, mainly in rapidly growing cities in resourcelimited regions where a lack of basic sanitation favors rodentborne transmission [10]. 
Relatively few cases of leptospirosis are recorded on the African continent mainly due to unawareness and difficulties in diagnosis in both human and animals; hence the disease is not well investigated [11]. However, the prevailing climatic and socioeconomic environments are favorable for a high incidence of this disease [12].

The incidence of leptospirosis in West Africa is largely unknown and data on carrier rates in small mammals are scarce $[13,14]$. In this region, leptospirosis has mainly been studied in Nigeria, a neighbor country of Benin, showing a high risk of exposure to leptospires. Application of the standard microscopic agglutination test (MAT) on sera collected from humans living in various parts of the country revealed a prevalence of $20.5 \%$ [15], while a serological survey in the Enugu area on distinct risk groups, including coal miners, butchers and slaughterhouse workers, farmers, and hospital laboratory personnel, revealed prevalence rates ranging from about 6 to $19 \%$ [16]. Serological and microbiological examination on slaughterhouse workers in the Nigerian state Plateau found a prevalence of $29.5 \%$ [17]. Furthermore, serological [18] and microbiological [19] investigations on potential natural hosts demonstrated infection rates ranging from $4.5 \%$ in brown field rats (Arvicanthis niloticus) to $23.5 \%$ in sheep.

In Benin, little is known about the actual impact of leptospirosis, particularly regarding the carrier rates in small mammals and the risk factors of human infection in urban zones. Previous investigations have been focused on human leptospirosis in Cotonou. A serological study on children hospitalized in the Centre National Hospitalier et Universitaire Hubert Koutoukou Maga (CHU) revealed a relatively low prevalence of 3.9\% [22]. On the other hand, Koundé and Zohoun [23] reported a prevalence of about $20 \%$ in sera of apparently healthy blood donors in Centre National de Transfusion Sanguine de Cotonou and $66.5 \%$ in sera from slaughterhouse workers. Consistent with these findings, investigation on 503 serum samples from people working in slaughterhouses and 244 samples from febrile patients by MAT showed a positive outcome in $54.7 \%$ and $75.8 \%$, respectively, of the samples [24].

These findings suggest that leptospirosis is an outstanding public health problem in Cotonou, Benin. However, the role that is played by rodents in urban epidemiology of this disease has remained unknown. The purpose of this study was to determine the prevalence of leptospirosis in small mammals in Cotonou as to assess their impact on urban leptospirosis.

\section{Materials and Methods}

The study was approved by the Ethical Committee of l'Université d'Abomey-Calavi of Benin, reference no. 208/ MCOT/SG/DRH/DDCPRS/SFERM.

2.1. The Trapping Quarter Selection. According to resident population and the degree of sanitary infrastructure expressed in terms of potential risk of leptospirosis, we distinguished four types of areas in Cotonou town for trapping rodents encompassing various districts denoted as quarters: (A) areas at high risks of contracting leptospirosis: quarters on the shores of the lake Nokoue and the lagoon of Cotonou devoid of sanitary infrastructures; (B) areas at moderate risks: quarters with moderate sanitation; $(\mathrm{C})$ areas with low risks: quarters consisting of areas with good sanitary infrastructures, including the embassy area; (D) nonresident putative high risk areas: market Dantokpa, market Ganhi, and Aïbatin (swamps).

2.2. Trappings. Trappings were done in 30 quarters in the risk areas as follows: 21 quarters in (A), 4 quarters in (B), 2 quarters in (C), and 3 in (D) (Figure 1(a)), and executed during November and December 2009 using specially made wire netting traps measuring $10 \times 10 \times 25 \mathrm{~cm}$.

Each trapping event was executed for three consecutive days (two nights) per quarter. Traps were baited with fish, set out in the morning of the first day, and checked for capturing early the second and third morning. Traps containing captured animals on the second morning were replaced. Captured rodents were collected and transported to the Laboratoire de Biologie Appliquée de l'Université d'AbomeyCalavi, Cotonou, Benin for determination.

2.3. Determination of Trapped Species. Trapped rodents were euthanized humanely by placing them in an iron box containing cotton wool soaked with chloroform or diethyl ether. Killed animals were then tagged for identification. Key criteria and illustrations developed by de Visser and coworkers [25] were used to identify the rodent species. Subsequently, animals were dissected aseptically and kidneys were obtained for molecular detection and identification of Leptospira and stored in alcohol $(96 \% \mathrm{v} / \mathrm{v})$ until DNA extraction.

2.4. Molecular Detection and Characterization of Leptospires. Analysis of kidney samples for the presence of leptospires was done on 90 specimens.

Approximately $25 \mathrm{mg}$ of renal tissue was cut into small pieces and minced prior to DNA purification using the QIAamp DNA Mini Kit (Qiagen, Hilden, Germany). DNA extracts were diluted a 10 -fold prior to amplification as to reduce the effects of residual inhibitors of the Taq polymerase, using the SYBR Green real-time PCR assay as previously described $[3,26]$.

For characterization, DNA was amplified and sequenced according to Victoria et al. [27]. Sequences of a panel of Leptospira spp. have been used as reference sequences to enable speciation. Leptospira strains and infections used in this study are listed in Table 1 . DNA sequence alignments were generated with Vector NTI 10 software (Invitrogen). Multiple alignments of sequenced nucleotides were carried out using Clustal X (version 2) and the phylogenetic tree was drawn based on Neighbor-joining method [20] using MEGA5 software [21].

In addition, an adapted Taqman real-time PCR was applied that could separate Leptospira species in two clades of homologous species using clade-specific probes targeting $\sec Y$ gene, that is, one clade, denoted as clade 1, consisting 


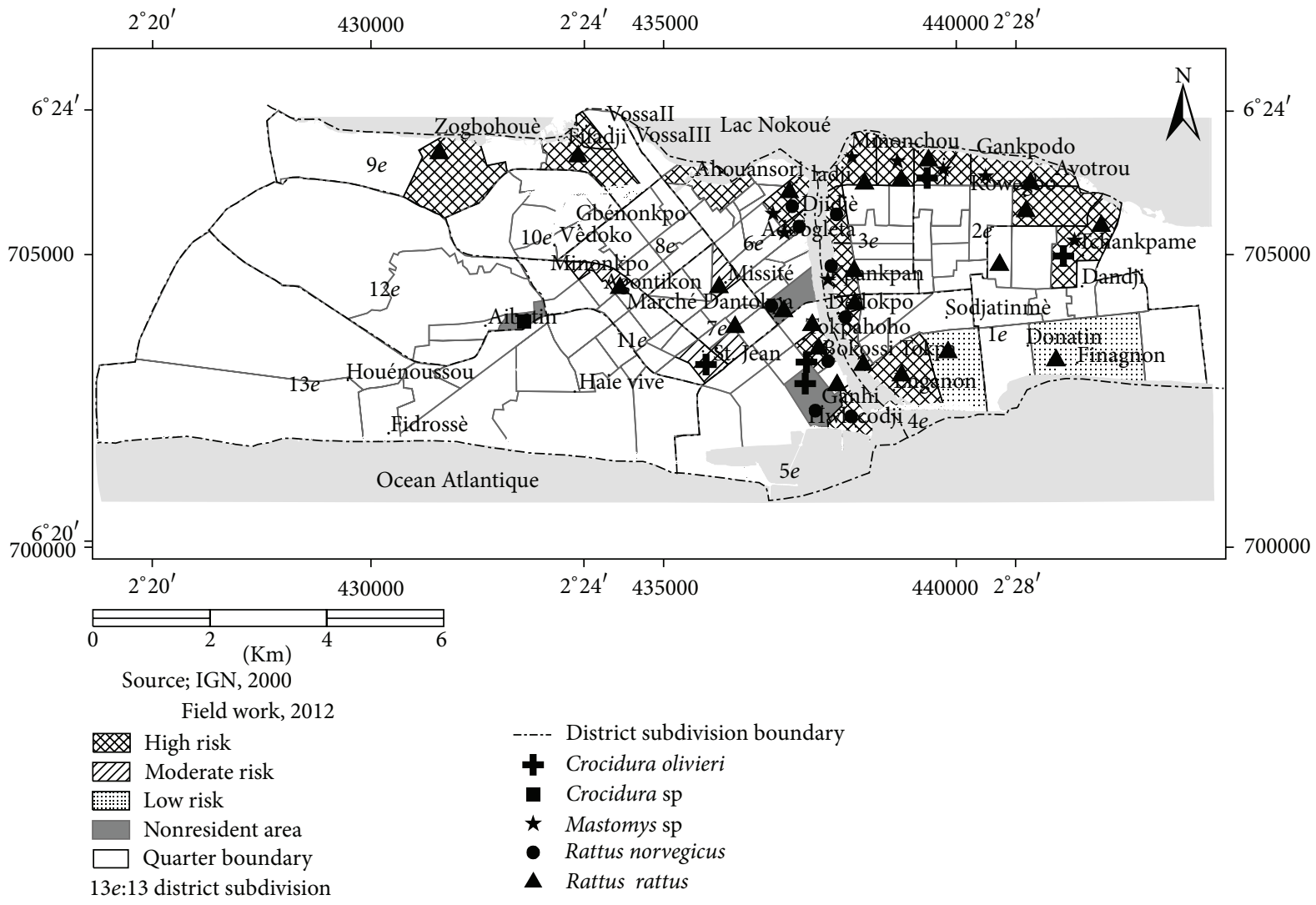

(a)

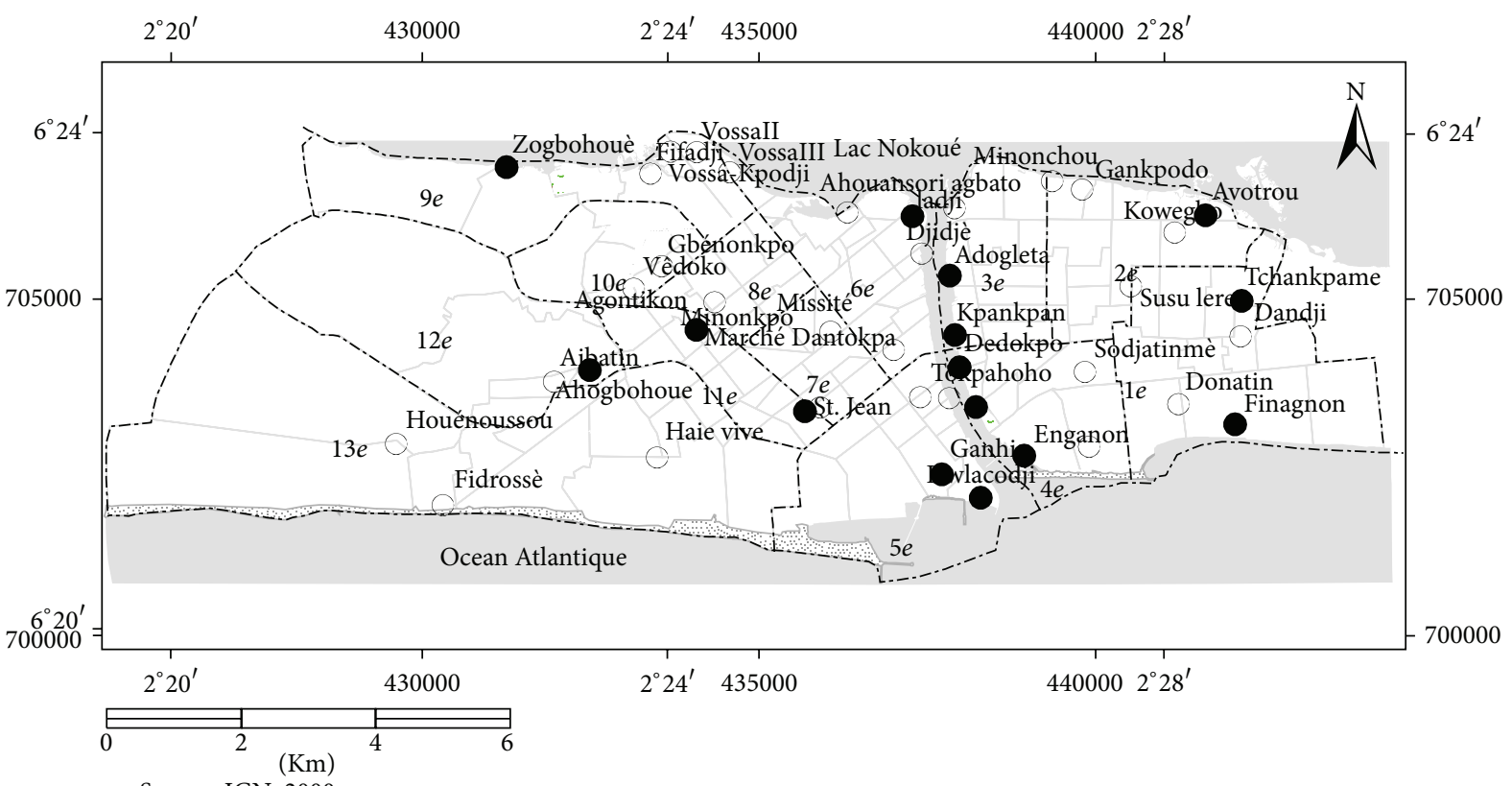

Source; IGN, 2000

Field work, 2012

- Positive PCR

13e:13 district subdivision

Negative PCR

Quarter boundary

-.--- District subdivision boundary

(b)

FIGURE 1: Map of Cotonou showing risk areas and catches of small mammals (a) and of Leptospira carriers based on positive PCR results (b). Symbols for risk areas and animal species are explained. Mastomys sp refers to unknown species of the genus Mastomys and Crocidura sp refers to unidentified species of Crocidura. 
TABLE 1: Leptospira strains and infections used in $\sec Y$ sequence-based phylogeny.

\begin{tabular}{|c|c|c|c|c|c|}
\hline Number & Code & Serovar & Strain & Species & Reference/genbank \\
\hline 1 & 1Bif. & Patoc & Patoc I & L. biflexa & NC_010842.1 \\
\hline 2 & 2Bor. & Ballum & Mus 127 & L. borgpetersenii & EU357953.1 \\
\hline 3 & 3Bor. & Castellonis & Castellon 3 & L. borgpetersenii & EU357955.1 \\
\hline 4 & 4Bor. & Hardjo-bovis & JB197 & L. borgpetersenii & СР000350.1 \\
\hline 5 & 5Bor. & Tunis & $\mathrm{P} 2 / 65$ & L. borgpetersenii & EU358064.1 \\
\hline 6 & 6Bor. & Nyanza & Kibos & L. borgpetersenii & EU358037.1 \\
\hline 7 & 7Bor. & Tarassovi & Perepelitsin & L. borgpetersenii & EU358057.1 \\
\hline 8 & 8Int. & Bratislava & Jez Bratislava & L. interrogans & EU357939.1 \\
\hline 9 & 9Int. & Canicola & Hond Utrecht IV & L. interrogans & EU357961.1 \\
\hline 10 & 10Int. & Gem & Simon & L. interrogans & EU358039.1 \\
\hline 11 & 11Int. & Hardjo & Hardjoprajitno & L. interrogans & EU357983.1 \\
\hline 12 & 12Int. & Hebdomadis & Hebdomadis & L. interrogans & EU357974.1 \\
\hline 13 & 13Int. & Icterohaemorrhagiae & RGA & L. interrogans & EU357997.1 \\
\hline 14 & 14Int. & Pomona & LT 1026 & L. interrogans & EU358017.1 \\
\hline 15 & 15Int. & Kuwait & $136 / 2 / 2$ & L. interrogans & EU357970.1 \\
\hline 16 & 16Int. & Lai & Lai & L. interrogans & AE010300.2 \\
\hline 17 & 17Int. & Muenchen & München C 90 & L. interrogans & EU357938.1 \\
\hline 18 & 18Int. & Pomona & Pomona & L. interrogans & EU358013.1 \\
\hline 19 & 19Kir. & Cynopteri & $3522 \mathrm{C}$ & L. kirschneri & EU358027.1 \\
\hline 20 & 20Kir. & Kambale & Kambale & L. kirschneri & EU358030.1 \\
\hline 21 & 21Kir. & Grippotyphosa & Moskva V & L. kirschneri & EU358028.1 \\
\hline 22 & 22Kir. & Bim & 1051 & L. kirschneri & EU357952.1 \\
\hline 23 & 23Kir. & Ramisi & Musa & L. kirschneri & EU358020.1 \\
\hline 24 & 24Kir. & Mozdok & 5621 & L. kirschneri & EU358015.1 \\
\hline 25 & 25Kir. & Ndambari & Ndambari & L. kirschneri & EU358001.1 \\
\hline 26 & 26Kir. & Kamituga & Kamituga & L. kirschneri & EU357963.1 \\
\hline 27 & 27Nog. & Argentiniensis & Peludo & L. noguchii & EU357960.1 \\
\hline 28 & 28Nog. & Carimagua & 9160 & L. noguchii & EU358068.1 \\
\hline 29 & 29Nog. & Huallaga & M 7 & L. noguchii & EU357950.1 \\
\hline 30 & 30San. & Beye & $1537 \mathrm{U}$ & L. santarosai & EU357981.1 \\
\hline 31 & 31San. & Darien & $637 \mathrm{~K}$ & L. santarosai & EU358066.1 \\
\hline 32 & 32San. & Gatuni & $1473 \mathrm{~K}$ & L. santarosai & EU358061.1 \\
\hline 33 & 33San. & Rama & 316 & L. santarosai & EU358063.1 \\
\hline 34 & 34San. & Rio & $\operatorname{Rr} 5$ & L. santarosai & EU358042.1 \\
\hline 35 & 35San. & Shermani & $1342 \mathrm{~K}$ & L. santarosai & EU357991.1 \\
\hline 36 & 36San. & Tropica & CZ 299 & L. santarosai & EU358005.1 \\
\hline 37 & 37Wei. & Coxi & Cox & L. weilii & EU358009.1 \\
\hline 38 & 38Wei. & Langati & M39039 & L. weilii & EU358065.1 \\
\hline 39 & 39Ben. & Undefined & 418 & L. borgpetersenii & This paper \\
\hline 40 & 40Ben. & Undefined & 440 & L. interrogans & This paper \\
\hline 41 & 41Ben. & Undefined & 480 & L. interrogans & This paper \\
\hline 42 & 42Ben. & Undefined & 617 & L. kirschneri & This paper \\
\hline 43 & 43Ben. & Undefined & 823 & L. kirschneri & This paper \\
\hline 44 & 44Ben. & Undefined & 896 & L. borgpetersenii & This paper \\
\hline 45 & 45Ben. & Undefined & 202 & L. borgpetersenii & This paper \\
\hline
\end{tabular}




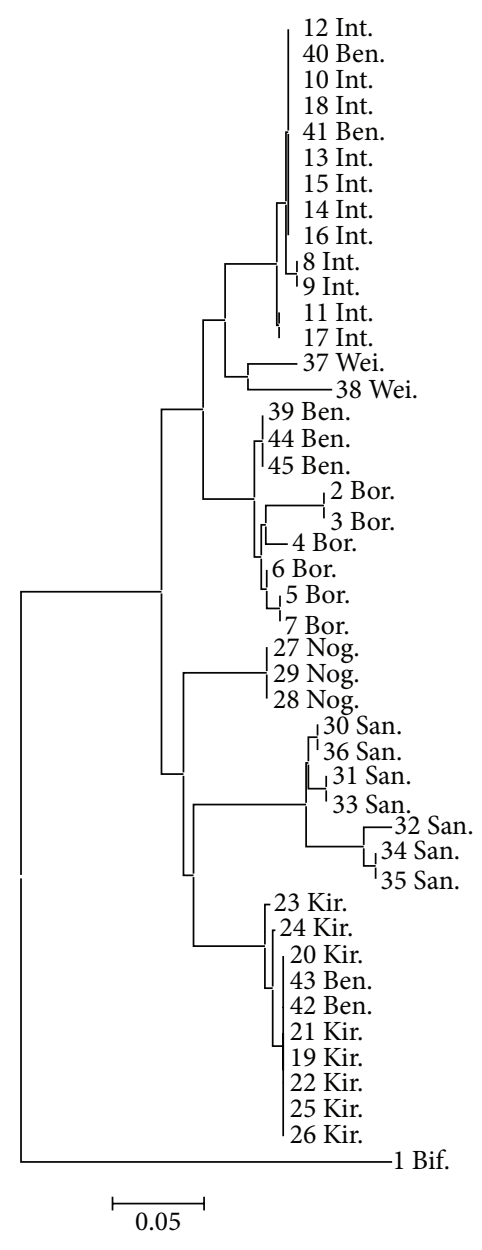

FIgURE 2: Phylogenetic tree of isolates from Cotonou and Leptospira reference strains. Phylogenetic tree of partial $\sec Y$ sequences. The evolutionary history was inferred using the neighbor-Joining method [20]. The optimal tree with the sum of branch length $=0.78179174$ is shown. The tree is drawn to scale, with branch lengths in the same units as those of the evolutionary distances used to infer the phylogenetic tree. All positions containing alignment gaps and missing data were eliminated only in pairwise sequence comparisons (pairwise deletion option). There were a total of 137 positions in the final dataset. Phylogenetic analyses were conducted in MEGA4 [21]. Codes of strains and infections are as listed in Table 1.

TABLE 2: Detection of leptospiral DNA by PCR in kidneys from rodents and shrews.

\begin{tabular}{lccc}
\hline Specie & $\begin{array}{c}\text { Number of } \\
\text { animals }\end{array}$ & $\begin{array}{c}\text { Number of } \\
\text { positive PCR }\end{array}$ & $\begin{array}{c}\text { Prevalence } \\
(\%)\end{array}$ \\
\hline Crocidura olivieri & 6 & 1 & 16.7 \\
Crocidura spp. & 1 & 1 & 100.0 \\
Mastomys spp. & 12 & 4 & 33.3 \\
Rattus norvegicus & 11 & 3 & 27.3 \\
Rattus rattus & 60 & 8 & 13.3 \\
\hline Total & 90 & 17 & 18.9 \\
\hline
\end{tabular}

of L. kirschneri, L. interrogans, L. meyeri, and L. noguchii and clade 2 comprising $L$. weilii, L. alexanderi L. borgpetersenii, and L. santarosai, identified by a $3^{\prime}$ end FAM labeled probe and HEX labeled probe, respectively. The sequence of the primer pair and the probes used in this assay were as follows: primer Gte F, 5'-AA(T/C)GT(G/A)ATGCCGATCAT-3', primer Gte R, 5'-GCGATTCAGTT(T/C)AA(C/T)CCTG3; probe KIMN, $5^{\prime}$-AGTAGTCAAGAATGGGCTGGATGFAM $^{\prime} 3$; probe WABS, $5^{\prime}$-AGTAGTCAAGAATGGGCTGGATG-FAM' 3 .

In short, this TaqMan PCR was performed on a CFX96 Bio-rad real-time PCR (Bio-Rad Laboratories, 2000 Alfred Nobel Drive, Hercules, CA, USA) using LightCycler 480 Probes Master (Roche Applied Science, 68298 Mannheim, Germany). The following reaction conditions were used; reactions were performed in a total volume of $20 \mu \mathrm{L}$ consisting of 1x LightCycler 480 Probes Master (Roche) of stock reagent containing FastStart Taq DNA polymerase, reaction buffer, dNTP mix (with dUTP instead of dTTP) and $6.4 \mathrm{mM}$ $\mathrm{MgCl}_{2}$. Forward and reverse primers were added at a final concentration of $600 \mathrm{nM}$ each and the clade-specific probes at a final concentration of $150 \mathrm{nM}$ each. The final concentration of target DNA was $250 \mathrm{pg} / \mu \mathrm{L}$ DNA. The amplification and hybridization protocol consisted of $5 \mathrm{~min}$ at $95^{\circ} \mathrm{C}$, followed by 40 cycles of amplification and hybridization $\left(95^{\circ} \mathrm{C}\right.$ for $15 \mathrm{~s}, 60^{\circ} \mathrm{C}$ for $\left.45 \mathrm{~s}\right)$. The resulting data were analyzed using the software provided by the CFX96 system (Bio-Rad CFX Manager version 2.0.)

\section{Results and Discussion}

3.1. Rodents Trapped according to Their Species. A total of 90 rodents and shrews were trapped and identified in order of decreasing number in Table 2 as Rattus rattus, Mastomys spp., $R$. norvegicus, Crocidura olivieri, and Crocidura spp. The majority of captures took place near fresh water sources, that is, the Aibatin swamp and the shores of Lac Nokoue and the river connecting the lake with the Atlantic Ocean, including the harbor area (Figure 1(a)). The capturing of a large number of Rattus spp. is consistent with their worldwide distribution [8] and the relatively high number of Mastomys spp. and Crocidura spp. is supported by previous studies in Africa [13].

In Cotonou, $R$. rattus was the most widely distributed rodent species in the study sample, originating from 24 of the 30 quarters, followed by $R$. norvegicus (9) and Mastomys spp. (8) (Figure 1(a)). This result is in agreement with the assumption that the black rat might be able to better adapt to climatologic and environmental conditions in West Africa, than the brown rat. Besides, the presence of $R$. norvegicus is generally restricted to coastal areas and sea ports while $R$. rattus has spread inland and is present in small towns and villages [28].

When separating rodent and insectivore species according to risk areas, we captured 53 R. rattus, eight $R$. norvegicus, twelve Mastomys spp., and three Crocidura olivieri in high risk areas (A); three $R$. rattus and one Crocidura olivieri in areas at moderate risk (B); two $R$. rattus in low risk areas (C); two $R$. rattus, three $R$. norvegicus, and three Crocidura spp., including two Crocidura olivieri, in putative high risk nonresident areas (D). The relatively high number of Mastomys spp. may 
TABLE 3: Leptospira spp. associated with species of small mammals and trapping sites.

\begin{tabular}{cccccc}
\hline & Sample & Clade number by TaqMan* & Species according to phylogeny & Small mammal species & Trapping location** \\
\hline 1 & 202 & 2 & L. borgpetersenii & Mastomys spp. & Tchankpamè \\
2 & 214 & 1 & - & Rattus norvegicus & Ganhi $+\mathrm{R}$ \\
3 & 418 & 2 & L. borgpetersenii & Rattus rattus & Agontinkon \\
4 & 440 & 1 & L. interrogans & Crocidura olivieri & St Jean \\
5 & 476 & 1 & - & Rattus rattus & Dédokpo R \\
6 & 480 & 1 & L. interrogans & Rattus norvegicus & Adogléta R \\
7 & 617 & 1 & Crocidura spp. & Aibatin (Bas-fond) \\
8 & 823 & 1 & L. kirschneri & Rattus rattus & Finagnon \\
9 & 896 & 2 & L. borgpetersenii & Rattus rattus & Avotrou \\
10 & 1015 & 2 & - & Mastomys spp. & Kpankpan R \\
\hline
\end{tabular}

${ }^{*}$ Clade 1 contains species L. interrogans, L. kirschneri, L. noguchii, and L. meyeri.

${ }^{*}$ Clade 2 contains species $L$. borgpetersenii, $L$. santarosai, L. weilii, and L. alexanderi.

** Trapping locations can be found in Figure 1.

be due to the presence of grasses around human dwellings near the lake (Figure 1(a)). This rodent may be found at a remote distance from habitations but is more frequently associated with markets, food stores, and farms [29].

3.2. Detection of Leptospiral DNA in Kidneys. We found a positive PCR signal in 17 of the 90 (18.9\%) kidney samples with carrier rates ranging from 13.3 to $33 \%$ in different species, with the exception of the single infected animal identified as Crocidura spp. (Table 2). It should be noted that these percentages underestimate the actual prevalence. Kidney tissues are notorious for the presence of PCR-inhibitory substances in the extracted DNA samples $[13,26]$. Although we have reduced the effect of inhibition by performing PCR on a 10-fold dilution, this may not exclude inhibition completely. Moreover, dilution also reduces concentrations of leptospiral target DNA below the lower limit of detection of the real-time PCR. Consequently, probably a proportion of infections have been missed and actual infection rates are higher than established. Unfortunately, it was not possible to assess the percentage of missed infections in this study.

All captured rodent and insectivore species had one or more PCR positive samples, suggesting that each of the species might be natural hosts for leptospires. These percentages are comparable to those in other reports from Africa. Investigations performed in South-eastern Africa, comprising Tanzania, Zimbabwe, Mozambique, and South Africa reported PCR positive results in about $11 \%$ of the rodent and insectivore populations, while culturing was successful in $1.6-7.4 \%$ of the animals $[12,13]$. Moreover, high carrier rates in small mammals in this region of Africa were further substantiated by high seroprevalence rates, exceeding $40 \%$, not only in small mammals but also in pet and farm animals as well as in humans (about 9-25\%) [13]. Similar high seroprevalences have been reported in previous studies in Nigeria [18, 19], further substantiating that significant proportions of small mammals are infected with leptospires and present a severe hazard to the public health in the western region of Africa.
3.3. Geographic Distribution of Carriers. The 17 PCR-deduced infected small mammals were captured in 15 locations distributed in $50.0 \%(15 / 30)$ of the selected quarters. Distribution of infected populations of small mammals is associated with presumed levels of risk areas as based on the absence of sanitation or the presence of fresh water sources; of 15 quarters with proven carriers of leptospires, 10 belonged to presumptive high risk areas, including potential high risk nonresident quarters (Figure 1(b)). The nonresident areas (D) include the presence of markets and swamps that present excellent survival and proliferation conditions for small mammals. Therefore, we assume that these nonresident areas might be foci of animal reservoirs of leptospirosis. Our findings are consistent with previous reports stating that in urban areas, infection is associated with overcrowding, poor hygiene standards, inadequate sanitation, and poverty, all of which typically occur in urban slums in developing countries $[30,31]$.

3.4. Leptospira Species versus Species of Small Rodents. Determination of Leptospira species was achieved by two approaches. DNA samples that were positive in the SYBR Green real-time PCR were subsequently subjected to a TaqMan real-time PCR, enabling so separate Leptospira species into two clades consisting of $L$. interrogans, $L$. kirschneri, L. noguchii, and L. meyeri (denoted here as clade 1) and $L$. borgpetersenii, L. santarosai, L. weilii, and $L$. alexanderi (denoted as clade 2), respectively [27]. This already enables speciation at a reasonable level because most common species in Africa are L. interrogans, L kirschneri, and L. borgptersenii. The distribution of L. santarosai and $L$. noguchii is limited to the Americas and L. weilli is a species of southeast Asia [32], while other pathogenic species comprise low numbers of strains with an insignificant distribution or have a doubtful composition [3]. This implies that this approach allows the identification of $L$. borgpetersenii to a reliable level and the presence of $L$. interrogans and/or L. kirschneri can be determined as well, albeit that further discrimination between these two species is not possible. 
Successful amplification by the Taqman PCR was obtained on 10 samples, separating 6 and 4 of these into clade 1 and clade 2 , respectively (Table 3 ).

In seven cases a PCR product was obtained that allowed sequencing, of the product and subsequent phylogenetic analysis. Four of these PCR reactors were designated to clade 1; two could be identified as belonging to $L$. interrogans and two belonged to L. kirschneri suggesting that these two species are similarly present in Cotonou. As expected, all three samples that were initially placed into clade 2 , were classified as L. borgpetersenii (Table 3 ).

PCR products, generated for sequencing, were relatively weak. A full sequence was only obtained from one sample (sample 418), while partial sequences were obtained from the other amplicons. To enable phylogenetic analysis all sequences were stripped to a segment of $139 \mathrm{bp}$ comprising reliable sequence data for all products suitable for phylogenetic analysis (Table 1) [27]. The phylogenetic analysis revealed that the strains belonged to the species, $L$. borgpetersenii, L. kirschneri, and L. interrogans (Figure 2). Phylogenetic separation of Leptospira strains to an appreciable level on a $245 \mathrm{bp}$ fragment of the $\sec Y$ gene has been reported before $[26,27]$ and is possible because of the high discriminative power of this gene [32-34]. However, the accuracy of this approach is hampered by further trimming the sequence down to about a half the size. Therefore, identification of the isolates on basis of this phylogenetic tree should be considered with some care. Nevertheless, our analysis shows that the L. interrogans isolates 440 and 480 are closely related to the serovars Gem, Hebdomadis, Icterohaemorrhagiae, Kuwait, Lai and Pomona. The L. kirschneri isolates 617 and 823 cluster together with serovars Cynopteri, Kambale, Grippotyphosa, Bim, Ndambari, and Kamituga. Sequences from isolates 418, 896, and 202 are identical and cluster with L. borgpersenii with serovar Kibos as one of the closest neighbours.

Detailed comparison with data from Africa is difficult due to the lack of survey related to the subject. Nevertheless, it should be noted that most of the related serovars within $L$. interrogans, L. kirschneri, and L. borgpetersenii originate or have been found in Africa or nearby islands (Gem, Kuwait, Kibos, Kambale, Ndambari, and Kamituga) and/or have a worldwide distribution (Icterohaemorrhagiae, Pomona, and Grippotyphosa) and, hence, support that the observations are consistent with the current knowledge on serovars circulating in this continent $[35,36]$.

Although the number of (presumptively) identified species is low, we looked for a pattern between the Leptospira spp. and the species of small mammals or location of trapping (Table 3 ). This allows some general conclusions. $L$. borgpetersenii seems to be confined to both $R$. rattus and Mastomys spp. On the other hand, L. interrogans and/or $L$. kirschneri was found in both $R$. rattus and $R$. norvegicus as well as in shrews (Crocidura). Presence of L. interrogans in shrews is not a common finding. Considering the short distances between the capture sites of rats and Crocidura oliviera in Cotonou (Figure 1(a)), it is conceivable to hypothesize that infection of $L$. interrogans in the shrews is maintained by transmission from the rat populations to the shrews. It is not clear from these data whether infections in the shrews are transient or whether the shrews form an infection reservoir of this usually highly virulent $L$. interrogans and hence present a persistent major risk for public health. Further research is needed to confirm or refute this possibility.

In conclusion, we have demonstrated that small mammals in Cotonou carry pathogenic leptospires at high rates. Thus our findings suggest a high exposure rate of human population in Cotonou to leptospirosis and predict leptospirosis as a high public health hazard. Further studies on potential infection reservoirs and on humans are needed to further substantiate this suspicion.

To date, health care workers and decision makers in Cotonou lack awareness of the presence of leptospirosis and diagnostic facilities are not in place. The current study as well as its continuation might raise alertness for this disease at public and veterinary health workers and decision makers in Benin. Because leptospirosis potentially is a treatable infectious disease, such increased awareness will contribute to better public and veterinary health care in Cotonou and in Benin in general.

\section{Acknowledgments}

The authors are grateful to the Government of Benin for the financial support of their study at University of Liege (Belgium). They thank all persons who helped made this study feasible, particularly those who have helped in the trapping and collection of rats: Florent Gnansounou, Honoré Houémènou, and Joël Dossou.

\section{References}

[1] H. Adler, S. Vonstein, P. Deplazes, C. Stieger, and R. Frei, "Prevalence of Leptospira spp. in various species of small mammals caught in an inner-city area in Switzerland," Epidemiology and Infection, vol. 128, no. 1, pp. 107-109, 2002.

[2] S. Y. A. M. Villanueva, H. Ezoe, R. A. Baterna et al., "Serologic and molecular studies of Leptospira and leptospirosis among rats in the Philippines," American Journal of Tropical Medicine and Hygiene, vol. 82, no. 5, pp. 889-898, 2010.

[3] A. Ahmed, L. B. M. Klaasen, M. van der Veen, H. van der Linden, M. G. A. Goris, and R. A. Hartskeerl, "Evaluation of real-time PCR and culturing for the detection of leptospires in canine camples," Advances in Applied Microbiology, vol. 2, pp. 162-170, 2012.

[4] S. A. Felt, M. O. Wasfy, W. F. El-Tras et al., "Cross-species surveillance of Leptospira in domestic and peri-domestic animals in Mahalla City, Gharbeya Governorate, Egypt," American Journal of Tropical Medicine and Hygiene, vol. 84, no. 3, pp. 420425, 2011.

[5] R. S. Machang'u, G. F. Mgode, J. Assenga et al., "Serological and molecular characterization of Leptospira serovar Kenya from captive African giant pouched rats (Cricetomys gambianus) from Morogoro Tanzania," FEMS Immunology and Medical Microbiology, vol. 41, no. 2, pp. 117-121, 2004.

[6] R. S. Machang'u, G. Mgode, and D. Mpanduji, "Leptospirosis in animals and humans in selected areas of Tanzania," Belgian Journal of Zoology, vol. 127, pp. 97-104, 2012. 
[7] A. B. Thiermann, "Leptospirosis: current developments and trends," Journal of the American Veterinary Medical Association, vol. 184, no. 6, pp. 722-725, 1984.

[8] N. B. Vanasco, M. D. Sequeira, G. Sequeira, and H. D. Tarabla, "Associations between leptospiral infection and seropositivity in rodents and environmental characteristics in Argentina," Preventive Veterinary Medicine, vol. 60, no. 3, pp. 227-235, 2003.

[9] B. G. Meerburg, G. R. Singleton, and A. Kijlstra, "Rodentborne diseases and their risks for public health Rodent-borne diseases and their risks for public health," Critical Reviews in Microbiology, vol. 35, no. 3, pp. 221-270, 2009.

[10] A. I. Ko, M. G. Reis, C. M. R. Dourado, W. D. Johnson, and L. W. Riley, "Urban epidemic of severe leptospirosis in Brazil," The Lancet, vol. 354, no. 9181, pp. 820-825, 1999.

[11] J. Holt, S. Davis, and H. Leirs, "A model of leptospirosis infection in an African rodent to determine risk to humans: seasonal fluctuations and the impact of rodent control," Acta Tropica, vol. 99, no. 2-3, pp. 218-225, 2006.

[12] G. F. Mgode, R. S. Machang'u, M. G. Goris, M. Engelbert, S. Sondij, and R. A. Hartskeerl, "New Leptospira serovar Sokoine of serogroup Icterohaemorrhagiae from cattle in Tanzania," International Journal of Systematic and Evolutionary Microbiology, vol. 56, no. 3, pp. 593-597, 2006.

[13] RatZooMan, 2012, http://www.nri.org/projects/ratzooman/ publications.htm. .

[14] M. Sankale, A. M. Sow, H. Ruscher, and H. Sarrat, "Leptospirosis in a Dakar hospital: results of a new survey," African Journal of Medicine and Medical Sciences, vol. 5, no. 3, pp. 213-220, 1976.

[15] C. A. Agunloye, F. O. Alabi, S. O. Odemuyiwa, and O. D. Olaleye, "Leptospirosis in nigerians: a seroepidemiological survey," Indian Veterinary Journal, vol. 78, no. 5, pp. 371-375, 2001.

[16] N. F. Onyemelukwe, "A serological survey for leptospirosis in the Enugu area of eastern Nigeria among people at occupational risk," Journal of Tropical Medicine and Hygiene, vol. 96, no. 5, pp. 301-304, 1993.

[17] A. O. Ezeh, A. A. Adesiyun, P. B. Addo, W. A. Ellis, A. A. Makinde, and C. S. Bello, "Serological and cultural examination for human leptospirosis in Plateau State, Nigeria," Central African Journal of Medicine, vol. 37, no. 1, pp. 11-15, 1991.

[18] C. A. Agunloye, "Leptospiral agglutinating antibodies in sheep and goats in South-West Nigeria," Israel Journal of Veterinary Medicine, vol. 57, pp. 28-30, 2002.

[19] A. A. Diallo and S. M. Dennis, "Bacteriological survey of leptospirosis in Zaria, Nigeria," Tropical and Geographical Medicine, vol. 34, no. 1, pp. 29-34, 1982.

[20] N. Saitou and M. Nei, "The neighbor-joining method: a new method for reconstructing phylogenetic trees," Molecular Biology and Evolution, vol. 4, no. 4, pp. 406-425, 1987.

[21] K. Tamura, D. Peterson, N. Peterson, G. Stecher, M. Nei, and S. Kumar, "MEGA5: molecular evolutionary genetics analysis using maximum likelihood, evolutionary distance, and maximum parsimony methods," Molecular Biology and Evolution, vol. 28, pp. 2731-2739, 2011.

[22] P. O. Dossou-Yovo, “Contribution à l'étude de la leptospirose chez l'enfant au C.N.H.U. de Cotonou: aspects épidémiologiques, diagnostiques et thérapeutiques," Mémoire, p. 107, Faculté des Sciences de la Santé, Cotonou, Bénin, 1999.

[23] T. Koundé and I. Zohoun, "Rapport d’activités. Projet Leptospirose au Bénin,” CEC Projet TS3-CT91-0035, 1994.
[24] P. T. Houngbo and J. N'gouize, "Premiers résultats de dépistage sérologique de la leptospirose à Cotonou et ses environs," Mémoire de DIT en TBH/ABM, p. 168, CPU/UNB, Cotonou, Bénin, 1995.

[25] J. de Visser, G. A. Mensah, J. T. C. Codjia, and H. A. Bokonon-Ganta, Guide préliminaire de reconnaissance des rongeurs du Bénin, Réseau Rongeurs et Environnement. CBDD.eCCooperation, Bénin, 2001.

[26] A. Ahmed, M. F. M. Engelberts, K. R. Boer, N. Ahmed, and R. A. Hartskeerl, "Development and validation of a real-time PCR for detection of pathogenic Leptospira species in clinical materials," PLoS ONE, vol. 4, no. 9, Article ID e7093, 2009.

[27] B. Victoria, A. Ahmed, R. L. Zuerner et al., "Conservation of the S10-spc- $\alpha$ locus within otherwise highly plastic genomes provides phylogenetic insight into the genus Leptospira," PLoS ONE, vol. 3, no. 7, Article ID e2752, 2008.

[28] N. G. Gratz and A. A. Arata, "Problems associated with the control of rodents in tropical Africa," Bulletin of the World Health Organization, vol. 52, no. 4-5, pp. 697-706, 1975.

[29] D. R. Rosevear, The Rodents of West Africa, Publication No. 677, British Museum (Natural History), London, UK, 1969.

[30] L. L. Colleen, D. S. Lee, B. C. Scott, and W. Philip, "Climate change, flooding, urbanisation and leptospirosis: fuelling the fire?" Transactions of the Royal Society of Tropical Medicine and Hygiene, vol. 104, no. 10, pp. 631-638, 2010.

[31] G. Mgode, A. Mhamphi, E. Katakweba et al., "PCR detection of Leptospira DNA in rodents and insectivores from Tanzania," Belgian Journal of Zoology, vol. 135, pp. 17-19, 2005.

[32] K. Nalam, A. Ahmed, S. M. Devi et al., "Genetic affinities within a large global collection of pathogenic Leptospira: implications for strain identification and molecular epidemiology," PLoS ONE, vol. 5, no. 8, Article ID e12637, 2010.

[33] N. Ahmed, S. Manjulata Devi, M. de los Á Valverde et al., "Multilocus sequence typing method for identification and genotypic classification of pathogenic Leptospira species," Annals of Clinical Microbiology and Antimicrobials, vol. 5, article 28, 2006.

[34] A. Ahmed and J. Thaipadungpanit, "Comparison of two multilocus sequence typing schemes for Leptospira species ," PLoS Neglected Tropical Diseases. In press.

[35] E. Kmety and H. Dikken, Classification of the Species Leptospira Interrogans and History of Its Serovars, University Press Groningen, Groningen, The Netherlands, 1993.

[36] S. Rahelinirina, A. Léon, R. A. Harstskeerl et al., "First isolation and direct evidence for the existence of large small-mammal reservoirs of Leptospira sp. in Madagascar," PLoS ONE, vol. 5, no. 11, Article ID e14111, 2010. 


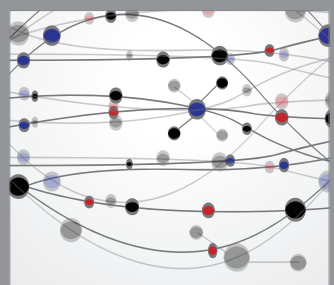

The Scientific World Journal
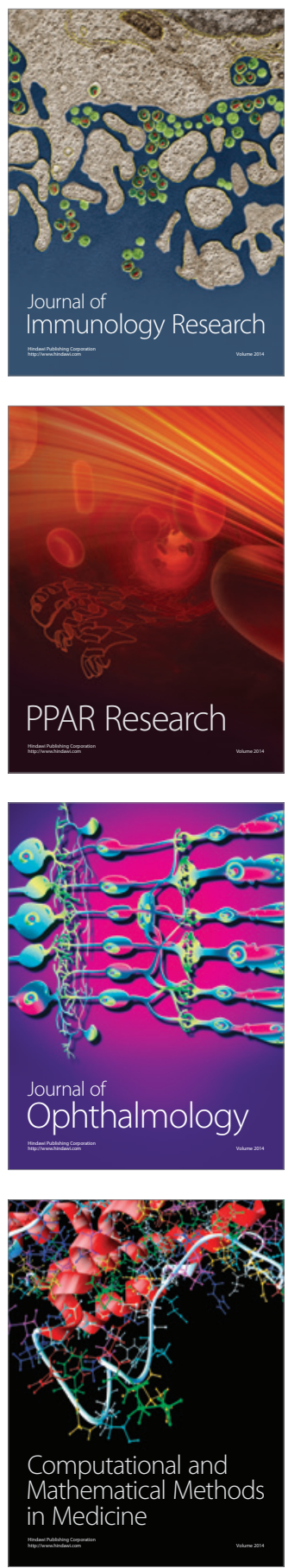

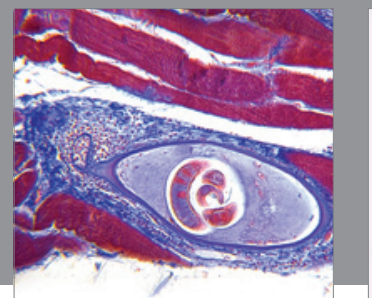

Gastroenterology

Research and Practice
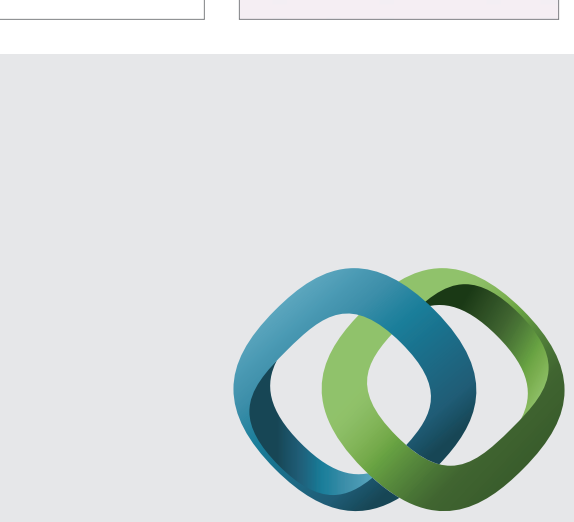

\section{Hindawi}

Submit your manuscripts at

http://www.hindawi.com
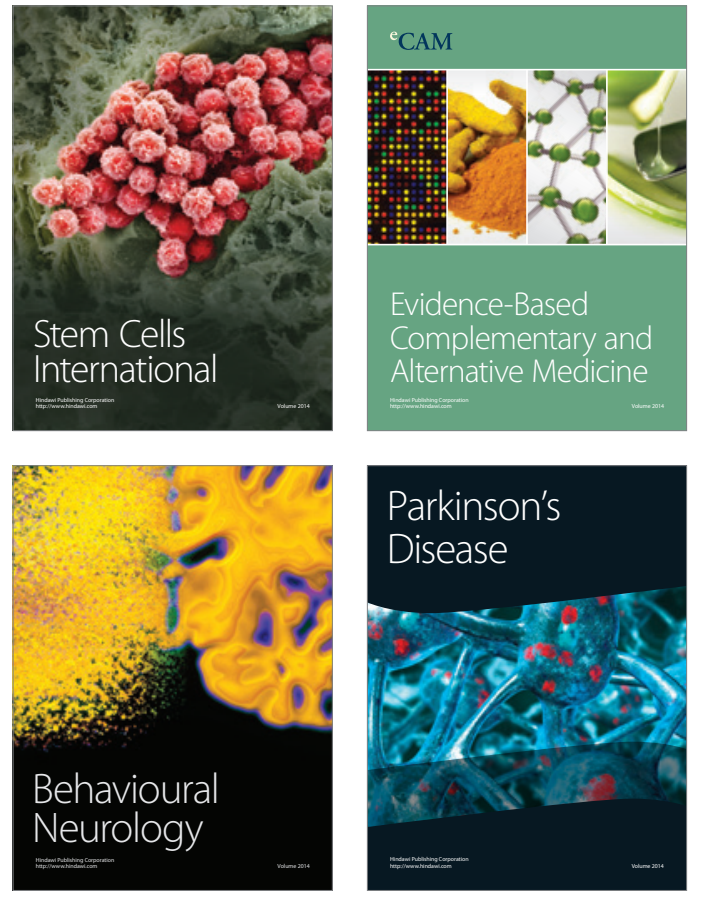
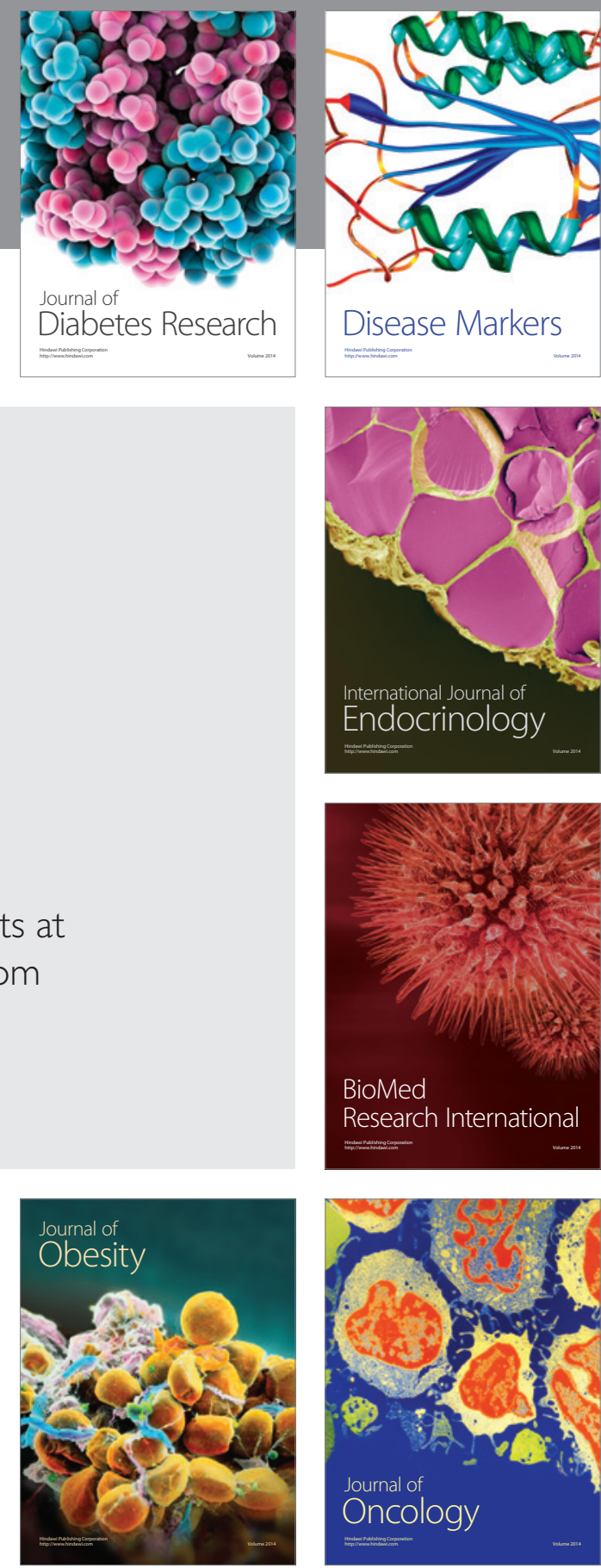

Disease Markers
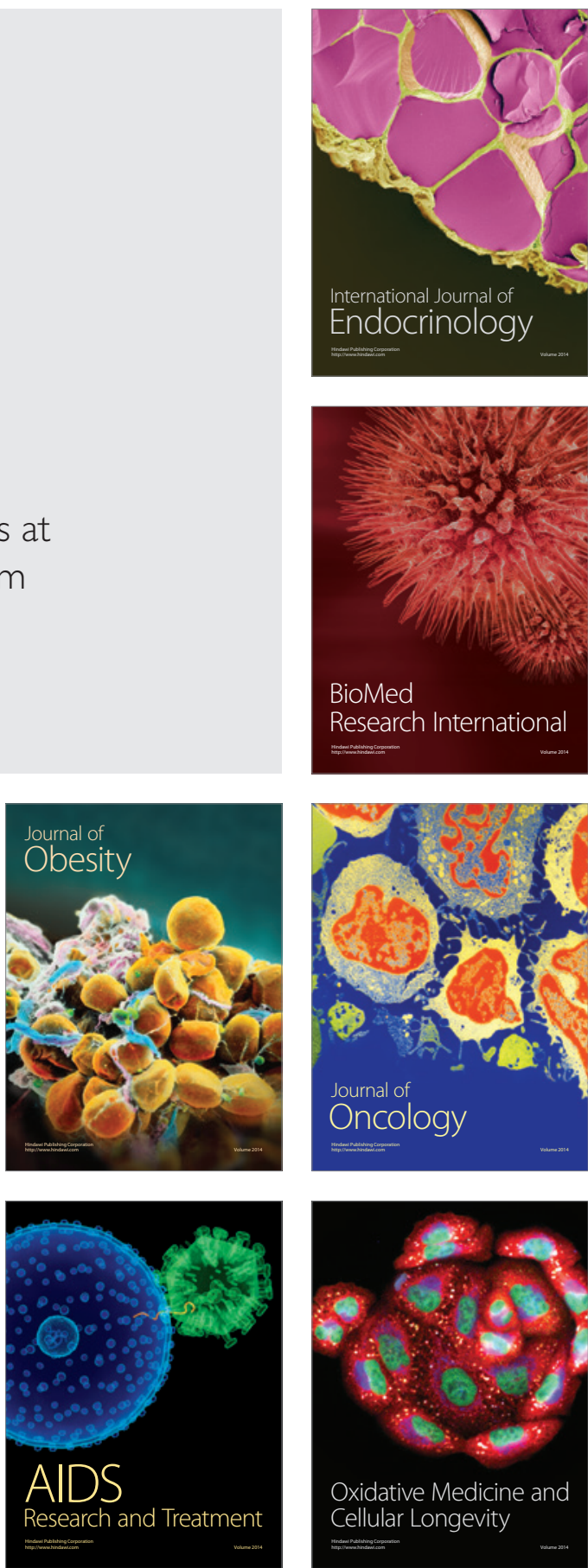